\title{
THE SUPERINTENDENT OF SCHOOLS ${ }^{\mathrm{x}}$
}

\author{
ELLWOOD P. CUBBERLEY \\ Professor of Education, Leland Stanford Junior University, \\ Stanford University, Cal.
}

A new profession.-As we look back over the three-quarters of a century during which the office of superintendent of city schools has been in existence, a few names stand out with particular prominence as those of men who have laid - often against tremendous obstacles, often in conflict and contest to the end of their careers, and often by the sacrifice of much that men hold dearthe foundation principles of the new work to which they gave the best years of their lives. Doing a pioneer work, and often misunderstood and unappreciated by those with whom they labored, these men patiently blazed a trail for others to follow. As a recent writer has put it, "each traveled the trail at his own gait, with rations and blanket only, and never knowing, though caring much, where each year's tramping would end."2 Out of this three-quarters of a century of trial, conflict, discussion, and experimentation, a profession of school supervision is at last being evolved.

School supervision represents a new profession, and one which in time will play a very important part in the development of American life. In pecuniary, ${ }^{3}$ social, professional, and personal rewards it ranks with the other learned professions, while the call for city school superintendents of the right type is today greater than the call for lawyers, doctors, or ministers. The opportunities offered in this new profession to men of strong character, broad sympathies, high purposes, fine culture, courage, exact training, and executive skill, who are willing to take the time and spend the energy necessary to prepare themselves for large service, are not

'This article forms chap. $\mathrm{x}$ in the author's forthcoming book, Public School Administration, to be issued in the early winter, and is reproduced here by permission of the publishers, Houghton Mifflin Company, of Boston.

${ }^{2}$ Gove, The Trail of the City Superintendent, p. 2 I5.

3 The following average salaries of superintendents of schools in the cities of different size in the United States for I9I2-I3 are taken from the recent report on teachers' salaries, prepared by the National Education Association and issued by the 
excelled in any of the professions, learned or otherwise, today. No profession offers such large personal rewards, for the opportunity of living one's life in molding other lives, and in helping to improve materially the intellectual tone and moral character of a community, offers a personal reward that makes a peculiarly strong appeal to certain fine types of men and women.

Importance of this official.-Potentially, at least, the most important officer in the employ of the people of any municipality today is the person who directs the organization and administration of its school system, and who supervises the instruction given therein. Actually, the condition frequently is otherwise, but where the superintendent of schools is of the type he should be, he renders a service the importance of which, in terms of character and future citizenship, is not approached by that of any other official in the employ of a municipality. In popular estimation, the mayor, the president of the city council, the chief of police, or the head of the fire department may occupy more important positions, but the far-reaching character of the services of a capable and energetic superintendent of schools transcend in importance any of these.

What the schools are in organization, administration, instruction, spirit, and purpose, and the position which they occupy in the eyes of the community, they are largely as the result of the actions, labors, manliness, courage, clear vision, and common-sense of the superintendent of schools. About him and his work the schools revolve, and it is largely he who makes or mars the system. What he is, the schools, under proper administrative conditions, become; what he is not, they often plainly show.

United States Bureau of Education (Bulletin No. 16, 1914). The maximum salary is higher now in some of the groups.

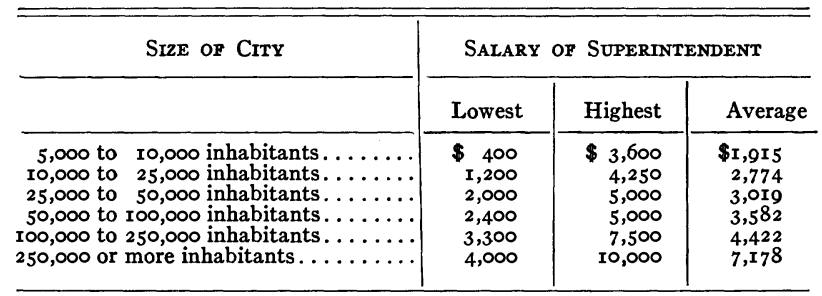

I Here, as elsewhere throughout this article, the masculine form is used, and for the simple reason that nearly all of our city superintendents are men. What is said, however, is equally applicable to women. 
Large duties of the office.-His is the central office in the school system, up to which and down from which authority, direction, and inspiration flow. $\mathrm{He}$ is the organizer and director of the work of the schools in all of their different phases, and the representative of the schools and all for which the schools stand before the people of the community. He is the executive officer of the school board, and also its eyes, and ears, and brains. He is the supervisor of the instruction in the schools, and also the leader, adviser, inspirer, and friend of the teachers, and between them and the board of education he must, at times, interpose as an arbiter. Amid all of his various duties, however, the interests of the children in the schools must be his chief care, and the larger educational interests of the community as a whole he must constantly keep in mind.

The position of superintendent of schools in a modern city, if properly filled, is a full man's job, and calls for the best that is in a strong, capable, well-trained, and mature man. It is a position for which a young man ought to be willing to spend many years in hard and painstaking preparation. To be able to obtain a small superintendency at thirty, and a large and important position at forty, is about what a young man desiring to prepare for the work should be content to expect. It is a position for which years of careful preparation should be made, and, given equal native ability, the more careful has been the preparation the larger is likely to be the ultimate success.

Perhaps it may not be out of place, at this point, to turn from the problems of school administration proper and devote the remainder of this chapter to a description of the professional preparation which a young man, desiring to prepare for school superintendency work, should make today; the type of professional experience he should acquire; and the kind of personal qualities he ought to expect to bring to the work. The following may be taken to represent a minimum professional preparation if any large future success is to be expected.

Education and training.-In the first place a good college education may be considered as an absolute essential for future work, and at least a year of graduate study doing advanced work in the study of educational problems is practically a necessity now. Men of large grasp and ability should not stop here, but, after a few years of practical experience, should go on and obtain their Ph.D. degree. 
The exact nature of the preliminary preparation is perhaps less important than that it should be good, and that it should challenge the best efforts of the student, awaken worthy ambitions, and stimulate the development of a high ideal of service. The preparation should be broad, and should early open up to the student permanent interests in fields of music and art, literature, history, science, and human welfare. These he needs for breadth and understanding. His future success as the head of a school system will to a rather large degree depend upon his intelligent understanding of the scientific and industrial world about him, his broad human sympathies, and his ability to meet people of culture and refinement on their own plane.

On top of this preliminary and general preparation the student needs to superimpose a technical preparation in educational theory, and a practical preparation in actual school practice. As early as the Sophomore year, certainly not later than the Junior, a brief introductory course on the place, purpose, and nature of public education and an introduction to educational theory can be taken with advantage. In the Junior and Senior years this should be followed with courses which give a good general introduction to the different fields of educational theory, history, administration, and practice. The graduate year should be devoted largely to advanced courses, and to the careful working out of some special problem in educational theory or practice. What is desired is a good introduction to the different fields and to the literature of education, and some practice in the methods by which educational problems are solved.

The years of apprenticeship.-All of this is merely preliminary, however. On top of this the candidate must now spend his apprenticeship and period of preliminary practice in his profession. ${ }^{\mathrm{I}}$ The five or six years which he now spends in teaching or in serving as a school principal ought to be years when he more than doubles the effectiveness of his general and professional collegiate preparation. If necessary, to avoid falling into a rut or getting a poor or

I This period of apprenticeship, which we may assume to be spent in a school principalship, involves the mastery of most of the details of school organization and administration as applied to a single school. This work will form the subject-matter of another book of this series, on The Organization and Administration of a School. 
one-sided experience, he should move about during this period. If the salary does not seem large enough to cover both married life and study, he should for a time resolutely put marriage aside.

During these years he should save as much time as possible for careful reading and study along the lines of his future profession. Above all, during these years, he should gradually crystallize for himself a working educational philosophy, to guide him in his future work and to vitalize all of his later procedure. He must seize intelligent hold of the conception that education stands for the higher evolution of both the individual and the race, and must relegate to their proper place in the educational scheme all of the details of organization, administration, and instruction. Without such a guiding conception administrative work soon becomes dull and fruitless routine.

Learning and working.- He should now accumulate a good working library along the line of his major interests. He should keep closely in touch, too, with all advancements and important experiments in his field, and with what other workers elsewhere are doing. He should welcome new school tasks, making himself as professionally useful as possible, and taking a deep personal satisfaction in doing difficult things. He should give himself good practice in developing an ability to speak well and easily and to write clearly and convincingly. He should mix to some extent with practical men of affairs, from whom he can learn much that will be very useful to him later on. If the opportunity offers to join a discussion club, especially if composed of men older and more mature than himself, he should embrace the chance. He may even lead in the formation of such a club himself. He should read biography, and study and try to imitate the best traits of the successful men he has come to know, both in literature and in real life. Often some old doctor or banker or lawyer in the community will prove worthy of some personal study.

He should, during this period, keep himself free from all practices, entanglements, clubs, and especially local social obligations, which are wasteful of time and energy and have in them little that is of permanent profit. He must, during these years, willingly accept work and burdens which lead toward his desired goal, and resolutely reject those which do not. He should know and remem- 
ber that the habit of hard and faithful work is one that is established but slowly, that it requires close watching of one's pole star to establish it, and that it is not fully established in most men until they are somewhere near thirty or thirty-five years of age. $\mathrm{He}$ should also know and remember that it takes about thirty-five or forty years of hard and faithful work to get ready to do something really large in life.

Rightly used, a half-dozen years after graduation can be spent, with great future advantage, in subordinate positions in the practical field.

Dangerous pitfalls.-It is during these years, however, that many a promising young man goes to pieces, so far as any large later usefulness in educational work is concerned. His college training gave him some feeling of mastery; he was trained there to do difficult things with some ease. When he goes to some smaller community he soon finds it unnecessary to work as he has done before. He also lacks the constant stimulus to sustained effort. Excepting a few lawyers and a few doctors, he is already one of the best educated men in the small city. His position, perhaps a principalship, gives him at once a special standing in the community. The people naturally look up to him as a man of more than ordinary training and importance. On the streets the men call him "professor," and pretty grade teachers and women with marriageable daughters seek him out and flatter his vanity. His daily work in superintending women and children, who usually accept his pronouncements as law, perhaps gives him an added importance in his own eyes. The presidency of a couple of societies or clubs adds further to his local importance.

He soon finds that, when he speaks to mothers' meetings and at church affairs, and even to fellow-teachers, he does not need to think carefully or to have anything of real value to say. He begins to feel his local importance; he begins to take life easily at least twenty years before he has earned the right; he ceases to read and study the problems of his work; he falls in with the local social life; and he gradually loses sight of the more distant goal he once set out to reach. Spoiled by too easy, too small, and too early successes, in a decade or less his possible usefulness for large work elsewhere has about reached the vanishing-point. 
Personal qualities necessary.-While good training and experience are of fundamental importance to the man who wishes to prepare for educational leadership, certain personal qualities must be added to both if any large success is to be achieved. The man who would be a superintendent of schools - the educational leader of a city-must be clean, both in person and in mind; he must be temperate, both in speech and in act; he must be honest and square, and able to look men straight in the eye; and he must be possessed of a high sense of personal honor. He needs a good time-sense to enable him to save time and to transact business with dispatch, and a good sense of proportion to enable him to see things in their proper place and relationship. He must have the manners and courtesy of a gentleman, without being flabby or weak. He must not be affected by a desire to stand in the community limelight, or to talk unnecessarily about his own accomplishments. He must avoid oracularism, the solemnity and dignity of an owl, and the not uncommon tendency to lay down the law. A good sense of humor will be found a means of saving grace here, and will many times keep him from taking himself too seriously.

He must be alert and able to get things done. This demands a good understanding of common human nature, some personal force, and some genuine political skill. He must know when and how to speak, but especially when and how to keep silent. He must know when and how to take the public into his confidence, and when not to tell what he desires or intends to do. He must know how to accept success without vainglory, and defeat without being embittered. He must keep a level head, so as not to be carried away by some new community enthusiasm, by some clever political trick, or by the great discovery of some wild-eyed reformer. $\mathrm{He}$ must, by all means, avoid developing a "grouch" over the situation which confronts him, for a man with that attitude of mind never inspires confidence, and is always relatively ineffective.

The qualities of leadership.- He must learn to lead by reason of his larger knowledge and his contagious enthusiasm, rather than to drive by reason of his superior power. The powers and prerogatives which are guaranteed him by law he must know how to use wisely, and he should be able to win new powers and prerogatives from the board largely by reason of his ability to use them well. He must 
constantly remember that he represents the whole community and not any part or fraction of it, and he must deal equal justice to all. As the representative of the whole community he will be wise not to ally himself at all closely with any faction or division or party in it.

He must, out of his larger knowledge, see clearly what are the attainable goals of the school system, and how best and how fast to attempt to reach them. From his larger knowledge, too, he must frequently reach up out of the routine of school supervision and executive duties into the higher levels of educational statesmanship. As a statesman, too, he must know how to take advantage of time and opportunity to carry his educational policy into effect.

By conferences, public and private, with leading citizens; by talks to parents at meetings at the schools; by taking the leaders among the teachers into his confidence; by dealing frankly and honestly with the press and the public; by his own written and spoken word, especially in his annual printed reports, and by inciting others to write and speak; and by tact and diplomacy in dealing with the members of his board, he must try to develop such a public opinion that the recommendations which he makes will go through without serious opposition, and be readily accepted by the people of the community. He must remember, though, that Rome was not built in a day; that it takes a long period of education to accomplish any really fundamental reform; and that it is usually not necessary to rush important matters to an immediate consideration.

It is now that the value of the long years of careful preparation becomes apparent. It is often said that only the man who is master of his calling, who overruns its mere outlines and knows more about the details of his work than anyone else with whom he must work, is safe. Out of his large knowledge of the details and processes of school work, gained in the years of apprenticeship in his calling, and out of the guiding educational philosophy which he has slowly built up for himself, he can see ends among the means and hope amid the discouragements, and be able to steer such a course amid the obstacles and trials and misunderstandings of city school control as will bring a well-thought-out educational policy slowly but surely into reality. To such a man larger and larger opportunities keep constantly opening up ahead. 